\title{
Vulnerability and Surviving Pattern of Elderly Migrants in Urban Mexico
}

\author{
Dr. Arun Kumar Acharya \\ Instituto de Investigaciones Sociales, Universidad Autonoma de Nuevo Leon, Mexico \\ Email: acharya_77@yahoo.com \\ Dr. Jose Juan Cervantes Niño \\ Instituto de Investigaciones Sociales, Universidad Autonoma de Nuevo Leon, Mexico \\ Email: yare95@gmail.com \\ Dr. Lilia Susana Padilla y Sotelo \\ Instituto de Geografia, Universidad Nacional Autonoma de Mexico (UNAM), Mexico \\ Email: lisupa@yahoo.com.mx
}

Accepted: July 02, 2012 Published: August 31, 2012

Doi:10.5296/jsr.v3i2.2267ＵRL: http://dx.doi.org/10.5296/jsr.v3i2.2267

\begin{abstract}
In the present paper, we have analyzed the vulnerability and surviving pattern of elderly migrants in Mexico. We have interviewed 156 Mexican elderly migrants in Monterrey Metropolitan Region during 2010-11. The study found that, majority of elderly migrates in search of a better economic opportunity in urban areas. Once they arrive to city, they absorb in informal economic sectors. Study found that most of the elderly do not have any job contract as well as they also earns very less compared to younger migrants. Most of the time employers ask them to work more hours without extra salary. Elderly migrants are suffering many kinds of physical violence as well as labor exploitation; even they also discriminated because of their physical condition. Study concludes that due to absence of social security and good public policies for elderly people, they are migrating in a hope to sustain their livelihood.
\end{abstract}

Keywords: Elderly migrants, Economic Vulnerability, Exploitation, Discrimination, Informal economy, Mexico

\section{Introduction}

Population ageing, the process by which older individual become a proportionally larger 
share of the total population is one of the most important demographic feature of the twenty first century. Initially, population ageing experienced by the developed countries, but currently this process has become more apparent for the developing nations. According to Population Division of United Nations, currently 11 per cent of world populations were more than 60 years and over, which projected to 22 percent by 2050, and it estimated that 36 per cent of this global aged population are living in the industrialized, more developed nations of the world (United Nations, 2011a). These countries have low fertility levels, which will ultimately generate populations exhibiting a high proportion of elderly persons.

The demographic transition under way in Latin America and the Caribbean reveals that region's population is gradually but inexorably ageing. This is a generalized process, in which all the countries are advancing towards the "graying" of their societies. Two characteristics of this process make it a matter of urgent concern. First, the population is ageing at a more rapid pace, and will continue to do so in the future, than the rates recorded in the past by today's developed nations. Second, this is taking place to a high poverty rate as well as a social inequity, a low level of institutional development and changes in family structure and composition (ECLAC, 2003).

As a result of immense demographic changes in other part of the world, Mexico is also experiencing profound changes in its demographic scenario in last 50 years. Data indicates that Mexican population over 60 years has increased from 5 during 1960 to 9 per cent in 2009 and expected to 28 per cent by 2050 (United Nations, 2010). It also estimated that by 2020, 1 in every 10 Mexican maybe older than 60 years. This shift in age structure is associated with population ageing has a profound impact on a broad range of economic, political and social conditions.

On the other hand, in Mexico, the sharp decline in mortality due to the expansion of health services, the low cost of importing effective drugs and a pro-natalist policy that sought to meet the labor needs of an expanding industrial sector and to populate the national territory, all favored rapid demographic growth during the twentieth century. Growth was especially rapid between 1954 and 1974, when the population increased by over 3 per cent per year. This was among the highest rates of population growth in human history. The country later adopted a new population policy that sought to reduce population growth, and this led to a rapid decline in fertility during the last quarter of the twentieth century.

Mexico's population has aged significantly in the past two decades. In 2010, the median age was 26 years meaning that there were equal numbers of people above and below age 26 . The median age in 2000 was 22 years while that in 1990 was only 19 years. Obviously, the number of older adults is growing much faster than the number of young adults and children. The Federal District has the highest median age by far with 31, followed by Nuevo León, Tamaulipas and Veracruz with 27. At the other end are Chiapas with 22, Guerrero with 23, and Puebla, Guanajuato, Durango and Aguascalientes with 24 (Rhoda and Burton, 2010). 
The study of Rhoda and Burton (2010) indicates; that in 2010, about 29.3 percent of the Mexican population was under age 15, compared to 34.1 percent in 2000 and 38.6 percent in 1990. On the other hand, the 2010 census reflects that 6.3 percent are over age 65 , up from 5.0 percent in 2000 and only 4.2 percent in 1990. The proportion in this older age group increased 50 percent in the past two decades. These changes are quite dramatic and represent major demographic change. The trend is expected to continue and have significant implications for education, elder care systems and regional demographic imbalance through migration.

Study on migration of elderly population is quite few in Mexico. This is because on the one hand, elderly migrants are not as much as other age groups, their floating rate is low; on the other, people think studying on migrants labors, migrants women and migrants children are important since they may face employment, reproduction and education problems. People will normally think that elderly migrants will not face such problems. Though the floating elderly population is still not so much, but currently it rising, from example in 2000 it was 3.7 percent and in 2010 it reached to nearly 5 percent. It will continue increasing in the future alone with the increasing of the elderly population, the increasing of the single child family and the acceleration of urbanization. Thus, the objectives of this study are to explore principal reasons of elderly people to migrate to urban centers as well as their survival strategy; for example, where they work, what kind of job they do, how many hours and day they work, what is their salary structure among other. This study examines the kind of discrimination and violence faced by elderly migrants in their work place. The present research carries out in Monterrey Metropolitan Area, one of the highly industrialized city in Mexico as well it is located closed to USA border. For this study, we have interviewed 150 elderly internal migrants (migrated to Monterrey prior to two years before at the time of interview) during 2010-11 with a semi structure questionnaire, who are working in the informal sector.

\section{Methodology}

\subsection{Data Analysis}

Collected data were coded and entered into a computer data file using SPSS software. We have used descriptive statistics and analysis of variances to analyze the demographic information and the variables related to migration of elderly people. A total of 156 Mexican elderly migrants (87 male and 69 female) were interviewed (age ranged from 60 and more years). All interviews were carried out in different places of the Monterrey Metropolitan Region.

\subsection{Migration and elderly people}


According to 2011 World Population Ageing Report given by United Nations, the whole world will experience an enormous increase in the number and proportion of older people in the next decades, and it is expected that during between 1980 and 2020, 65 and more years population will get double, one third of this will live in industrialized and developed countries. The temporal evolutions of the elderly population or aging of society is an often overlook phenomenon of demographic transition. When fertility and mortality rates are high, the relative size of an aging population is small (United Nations, 2011b).

One of the principal mechanism which generates an uneven spatial distribution and growth pattern for the older population is elderly migration. Most elderly people do not relocate and those who do make mostly short distances moves. The motivations for those moves are events, for example widowhood, disability, or neighborhood change. Nevertheless, long distance migration of older retired people is increasing in many economic advanced nations (Rogers, 1992). The main reason for this tendency is improved health, more generous pension arrangements and "the growing absolute and relative size of the older population (Rogers, 1992). Each move is influenced by a multitude of factors such as: 1. Push and Pull factor, 2. Housing, 3. Environment, 4. Family and social network and 5. Accessibility to services, life style influences.

\subsection{Push and Pull Factors}

Push factors can see as, which involve the decision to move away from one's current residence. Pull factors are those, which make a certain region attractive to move to, for example miles of coastline (Valerio 1997).

\subsection{Housing}

Several different studies on elderly people and their behaviors came to the solution that mainly those retirees are likely to move to another destination whose present housing environments do not fit in their desired lifestyle anymore. In some cases, for example, the security in their neighborhood declined, or lot of friends, which used to live there moved away. In general, they do not feel comfortable anymore.

\subsection{Environment}

More and more elderly migrations cover longer distances in search of amenity-rich communities with sunnier, warmer and recreationally more enjoyable environments. As Rodgers and Longino point out, images of how the retirement shall be like are frequently draw from leisure or vacationing experience. This could be either childhood summer camps or family vacations, which have a powerful influence on the lifestyle images of retirement (Rodgers 1992, Longino 1992).

\subsection{Family and Social Network}


Some research indicates that elderly people migrates those place where they can stay close to their child and friends (Longino 1992).

\subsection{Accessibility to service, life-style influences}

According to Longino (1992), some elderly people seek a change in their lifestyles, for which they change the territory and some find that they must relocate in order to reestablish their desired lifestyles because their environments around them have changed.

On the other hand, there are two basic models that explained the reason of elderly migration, such as: Wiseman's (1980) behavioral model and Northcott's (1988) social demographic model.

\subsection{Behavioral model of elderly migration}

Wiseman's (1980) behavioral model explained that older people migrate in search of better residential satisfaction. According to author, the idea of migration can be stimulate by one or more triggering mechanisms, which include change in life cyclical stage, age related losses and critical events, environmental incongruence, change in preferred lifestyle and forced movement. These mechanisms reflect by various pull factors, for example, kinship networks and push factors such as environmental stress. The movement of older people affected by a set of endogenous and exogenous factors. The endogenous factor comprises personal resources such as income, health status including their experiences on migration, whereas, exogenous factors are related to the living cost, housing market and their social network.

\subsection{Social demographic model of elderly mobility}

Northcott's (1988) social demographic model provides an explanatory framework for migration decision. A change in residence, including a given type of move and destination, results from one or more mechanisms; Objective factors - Subjective factors - Mobility. Objective variables such as personal characteristics such as; age, income, health features of the place origin and destination i.e. access to services, amenities, presence of kin and friends and intervening obstacles such as distance and cost of moving, can have direct impact of decision to move. The indirect effects of objective factors can also be exerted through the decision making process such as declining health, familial relationship etc,. Although subjective factors have direct effects on mobility the model also emphasizes the role of certain objective attributes such as social class and ethnicity in shaping one's attitudes, values and expectations which turn influence the migration decision.

From the above theoretical discussion it is clearly appears that elderly migration is purely a non-economic movement. It is true in the case of developed nations, where elderly people have economic and social security, but at present, there are developing countries where 
ageing process is growing concern and due to absence of social and economic security elderly people migrate to different urban centers in search of employment, basically to informal sector. This aspect has not widely discussed in the elderly people. Thus in this paper, we have focused that elderly migration in the case of developing countries is purely an economic based like as other migration flow.

\section{Demographic profile of Mexico}

Mexico's demographic transition has followed a typical profile, the pre-transitional phase that lasted until about 1930, the first stage saw a rapid decline in mortality while birth rates remained fairly steady and even rose between 1945 and 1960. The second phase began around 1970 when the decline in fertility, which began during the 1960s, became more rapid. The third stage of the process, when the birth and mortality figures converge, will occur during the first half of the twenty-first century. During the year 1921, the population growth rate was 1.4 per cent and it was 1.7 percent in 1930 and further to 2.7 per cent in 1950 and 3.5 per cent in 1965. As a consequence of the decline in fertility, the pace of population growth then began gradually to decrease, to 3.1 per cent in 1970, 2.3 per cent in 1985, 1.3 per cent in 2000 and currently it is less than 1 percent (Partida-Bush, 2005).

The general falls in mortality was so rapid that the cumulative reduction in the risk of death between 1930 and 2001 amounted to 82 per cent for men and 86 per cent for women. As in many other countries, Mexican mortality fell slowly during the 1960s. The pace of decline picked up later, but was not as rapid as in earlier years. A rapid and sustained decline in mortality took place beginning in the 1930s, in a context of far-reaching economic, political and social reforms. Among the main determinants of the sharp decline in mortality are the expansion of education services and sanitation infrastructure and the extension of health services. The latter has been a significant factor ever since the creation of the Mexican Social Security Institute (IMSS) in 1942 and the conversion of the Department of Health into the Ministry of Health in 1943. On the other hand, in 1930, the life expectancy at birth was 35.9 years, whereas, in 2010 it was 75.6 years. Progress was greatest between 1942 and 1960 when there was an increase of almost one year in the average length of life for each calendar year (Partida-Bush, 2005).

The decline in fertility did not begin until the mid-1960s. The high and even rising rates before then reflected the pro-natalist policy prevailing in the country during those years. Families had about six children in the early twentieth century, reaching a maximum of 7.2 children at the beginning of the 1960s. The gradual spread of the practice of family planning - as part of a new policy that sought to regulate population growth in accordance with the agreements adopted at the 1974 United Nations World Population Conference in Bucharest - contributed to advancing the fertility transition in Mexico. The total fertility rate (TFR) fell to six children per woman in 1975, five in 1979, four in 1985 and three in 1994, and has now reached to 2.1 children (Partida-Bush, 2005). 


\section{MInstitute Macrothin}

The various phases of demographic transition have left their mark on the age structure of the Mexican population, as can be seen from the figure 1. The data indicates that during the decades 70s Mexico had the demographic transition, for which we can observe a fall in the 0 to 4 and 5 to 9 age groups population and a sharp increase in 20 to 40 as well as elderly population. From the figure 1 it is appear that, after the years 1990 the elderly population in Mexico has started increasing at a higher rate compared other age groups, except 20 to 40 (INEGI, 2011) ${ }^{1}$. According to Instituto Nacional de las Personas Adultas Mayores (INAPAM) currently about 10 million (9 percent of total population) are elderly population and it is expected to reach 15 million in 2015 and 36 million in $2050^{2}$.

\section{Figure 1: Population distribution according to age groups in Mexico during 1950-2010}

On the other hand, we have analyze the population of 0-4 years and 60 years and more during the years 1990, 1995, 2000, 2005 and 2010 (see figure 2). From the flowing figure, we can clearly observe that in after 1995 there is steady growth in elderly population (60+ years) and at the same time; the 0-4 population is declining. During the year 2005 there was a transition between infant and elderly population in Mexico, which explained that Mexico is moving toward a ageing society.

\section{Figure 2: Infant and elderly population distribution in Mexico during 1990-2010}

It is a clear indication that elderly population in rise in Mexico, but according to Consejo Nacional de Evaluación de la Política de Desarrollo Social (CONEVAL) in 2010 around 3.5 million elderly people are suffering from multidimensional poverty, whereas around 0.8 million are suffering from extreme multidimensional poverty. Data indicates that among 3.5 million elderly 66.2 percent were illiterate, whereas 26.3 percent were do not have any kind health services, 28.8 percent didn't have any kind of social security and around 22 percent elderly had limited alimentation (INEGI, 2012) ${ }^{3}$. Data of elderly people living in rural areas indicates that they need to work in order to secure a minimum income for their survival. Due to absence of universal pensions systems and any kind governmental help are non-existent in rural Mexico, thus these ages people prefer to migrate to urban centers in search of employment. It has seen that upon their arrival elderly people occupied in the informal sector. In the figure 3 we have interpreted how the number of elderly migrants increasing in informal sector in the case Monterrey city. The figure shows that though there is little decline during 2000-05in number of elderly in informal sector, but it increases after 2008, due to global economic crisis.

\section{Figure 3: Number of elderly migrants in informal sector in Monterrey}

\section{Socio-demographic structure elderly migrants in Monterrey}

\footnotetext{
${ }^{1}$ Estadísticas a Propósito Del Día Internacional De Las Personas De Edad, INEGI, 2011 http://www.inegi.org.mx/inegi/contenidos/espanol/prensa/default.asp?c=269\&e, 05-05-2012

${ }^{2}$ http://www.inapam.gob.mx/index/index.php?sec=16\&clave articulo=136\&formato=print, 05-05-2012

3 INEGI (2012), Estadísticas a Propósito del día del Niño, datos nacionales, Aguascalientes, AGS., a 30 de abril de 2012.
} 
Universal literature on migration indicates that migration is a phenomenon of younger ages, which no longer may be true which we have seen from our analysis. In this study, we have classified the elderly migrants into three categories; such as 1 . Young old (60-70 years old), 2. Old old (71-80 years old) and 3. Very old (more than 80 years old). Result indicates that, for both male and female migrants there is no major differentiation on ages according, majority of migrants are young old and old. As we know, ages play an important role in the labor market, but our analysis indicates that employers prefer to contract an elderly in a lower salary as they living in vulnerable condition, as an employer said:

for me it is very convenient to give contract to a aged people, because they are very vulnerable and need money desperately, also if I ask them to work for more timer they didn't say "no" as they need earn money.

In term of educational pattern of elderly migrants, we have seen that; male are mostly more educated compare to their counterpart, whereas the percentage of illiterate is higher among female elderly than the male (see table 1).

\section{Table 1: Demographic characteristics of elderly people in Monterrey}

\section{Family and Living arrangement of elderly migrants}

Researches, for example of Valerio (1997), Wong, et.al (2007) and Capron \& Arellano (2010) states that mobility of married elderly is less compare to widowed, single, divorced or separated, but our study obtained a different results. Though, there are numbers of widow male and female among elderly migrants, but analysis indicates that majority (more than 60 percent of male and around 50 percent female elderly migrants) of them are currently married and living with their partner. It is clear in the context of Mexico, mobility of currently married elderly migrants is higher, it is because once they retired from the job, to sustain and maintain their family expenditure, they move in search of employment, it is also indicates the absence of support (socio-economic) from their children.

On the other hand, when we asked the elderly migrants with whom currently they are living in Monterrey; nearly 60 percent male and around 45 percent female elderly migrants said that they are living with their spouse. Also, data indicates that more than 30 percent of female migrants are currently living with their son and daughters in Monterrey, which is almost two times higher than male elderly migrants. We obtained from the analysis that nearly one fourth of the total male migrants live with their brothers, sisters and with their neighbors, which is nearly 22 percent in the case of female elderly migrants. Result on number of children of elderly migrants, it seen that majority of migrants have more than three children (see table 2).

\section{Table 2: Family dynamic and living arrangement of elderly migrants in Monterrey}

In the table 3, we have analyzed the standard of living index (SLI) of elderly migrants, into 
three categories; such as higher, medium and low, considering following variables:

\section{Table 3: Variables of standard of living index (SLI) of elderly migrants}

Taking into above variables, we have interpreted the standard of living index (SLI) of elderly migrants in the figure 4. Results indicate that, 60 percent (60.9 percent male and 58.2 percent female) of elderly migrants are having medium level of standard of living. It is interesting to observe that almost nearly twice percentage male elderly migrant compared to female elderly migrants are in high category of standard of living and similarly, one-third women migrants are in low category of SLI compare to one-fourth male migrants.

\section{Figure 4: Standard of Living Index (SLI) of elderly migrants in Monterrey}

\section{Employment status and support from children}

Capron and Arellano (2010) pointed out that elderly migrants are more vulnerable compared to other migrants due to their ages. These categories of migrants struggle to get a decent job, thus they preferred to occupy in the informal sectors. Data in employment status of elderly migrants shows that (see table 4) nearly 85 percent of women engaged as street vendor, domestic servant and sweeper, whereas, majority of men are engaged with kind of job like street vendor, taxi driver, sweeper, mechanic and as construction labor. From the table we can also observe that there is complete job segregation for both male and female.

\section{Table 4: Current income source of elderly migrants in Monterrey}

On the other hand, when we analyze the support received by the elderly migrants from their children. In traditional Mexican society, the cultural norm said that is the responsibility of children to take care of their parents during their old age. Although this cultural norm has been weekend in recent days, but still it is dominant in some sector of the Mexican society, which we can see from the following result. Nearly 78 percent female elderly migrants received financial support from their children compared to their counterpart (see table 5), whereas, more male elderly migrants received instrumental help, for example cooking food, cleaning house, washing clothes etc. compared to female migrants. It is necessary to mention that for household work still male feel that it is not their job. On emotional support, we found no much difference among the female and male migrants, but female migrants depends more on emotional support on their children compared to male.

\section{Table 5: Support receive from children by their elderly migrants in Monterrey}

To understand the quality of life elderly migrants as well as the current living status, we asked a question on their monthly income (see table 6). Analysis found that 13 percent of male elderly migrants and one fourth of total female migrants receive less than 1500 pesos ${ }^{4}$

\footnotetext{
${ }^{4}$ In Mexico 12 pesos is $\$ 1$ USD
} 
per month. Similarly, nearly 43 and 44 percent of male and female elderly migrants earn 1500 to 3000 pesos per month, whereas 15 percent of male and 19 percent of female migrants said their monthly income is 3000 to 4,000 pesos. However, we found that one-third male migrants and one-tenth female migrants earn more 4000 pesos per month. This analysis on salary distribution indicates that female elderly earn less than male elderly migrants.

\section{Table 6: Monthly income of elderly migrants in Monterrey}

\section{Working hour and dynamic of employment}

In this section, we have discussed the working condition of elderly migrants. Analysis reflects that there is not much difference in working hours of elderly migrants in term gender. Fifty percent of male and female migrants work in between 6 to 8 hours per day, whilst 20 percent of both male and female elderly migrants work more than 9 hours daily (see table 7). Similarly, this study found that nearly 60 percent of male and female elderly migrants work 5 to 6 days in a week, which give an impression that migrants have only a day for rest, whereas, in the case of 30 percent both sex migrants they work whole week. This indicates that they do not have at least a day for rest. We have seen from the interviews that some migrants prefer to work whole week in a hope to earn some extra money through tips and payment of extra hours/day.

\section{Table 7: Hours and Days of working of elderly migrants in Monterrey}

Our analysis on dynamic of employment of elderly migrants said that 80 percent of male and female migrants do not have any fixed contract in their job, which indicates lack of stability in their job. Thus, on question of job stability, we found that nearly 65 percent of male and two third of female migrants posses a daily basis contact, whereas 21 percent male and 13 percent female migrants said their contract is for few months and nearly 15 percent male and 12 percent female migrants have their contract for few weeks (see table 8). The question on working shift, we have seen that majority (71 percent male and 63 percent female) of migrants have morning shift, nearly 36 percent of female migrants works in afternoon, 10 percent of male migrants work during night. From above results, we conclude that elderly migrants are more vulnerable towards the job exploitation, as they do not possess any fixed and signed contract, as well as their job stability is very less and even there are migrants who are working during the night.

\section{Table 8: Dynamic of employment of elderly migrants in Monterrey}

\section{Violence and exploitation against elderly migrants}

We can perceive from earlier analysis that elderly migrants are very vulnerable towards the discrimination and violence because of their physical condition. In literatures, it is not well documented the problem faced by elderly migrants, thus it is important to analyze how and 
what kind of discrimination faced the elderly migrants. Table 9 represents the analysis on physical violence, labor exploitation and racial discrimination suffered by the elderly migrants by their employer and colleagues. Result indicates that more than 50 percent of female migrants have suffered physical violence, labor exploitation such as working more hours without paying extra money, salary reduction, forced to work more days and racial discrimination because of their age and belong to indigenous group. Though, the less percentage of male migrants who have suffered violence, exploitation and discrimination, but looking into the situation of elderly people we feel that there is no difference among male and female.

\section{Table 9: Violence and labor exploitation against elderly migrants}

\section{Conclusion}

Age is an important factor for migration, and we have seen that; rates of moving usually peak between the ages of 18 and 30, and generally decrease until very late in life, it is perhaps because of failing health forces. But, currently migration pattern is much more large and diverse compared to other time. At the beginning of 20st century, it has seen that only young people were migrating in search of better opportunity, but at present, migration of elderly people has brought an attention, which we have seen in Mexico.

The rapid decline in fertility and mortality level and increases in the life expectancy rate has taken Mexico towards an ageing society. In Mexican society generally children are assumed the cost and benefits of living with their parents compared to alternative living arrangements and to choose the arrangement that offers that most highly valued benefits.

In the present study, we have observed that elderly people both male and female are migrating to cities in search of employment and better opportunity, as they do not receive any social security from government, including for some people their pension is not sufficient. It has also seen that elderly people do not get opportunity in formal sector; they prefer work in informal economy. Our study indicates that; male elderly work as street vendor, taxi driver, mechanic, sweeper and laborer in construction sector, whereas female elderly mainly occupied as street vendor and domestic servants. In term of their monthly income we saw that elderly do not earn according to their expectation, majority of elderly migrants earn 1500 to 3000 pesos per month. Though, salary is very less, still they prefer to work; as a migrant said: I came Monterrey thinking that I will earn more money, in south (south of Mexico) people say that Monterrey is city of money, but it is not true...my monthly income is around 3000 pesos, it is not sufficient.... but I cannot go to other cities for better opportunity, because I am no longer young and changing a place mean for us need more time for adjustment... apart from that every day I am also getting more viejo (old), who will give me more salary...so whatever I am getting trying to adjust on it....

It is evident that elderly people faced many kind of discrimination not only in term of salary, also in term of their working hours and day. Study found that elderly people hardly get time 
to take rest during weekend. For most of them weekend does not exist. Some migrants work six days in a week and there are high number of elderly who works seven days of a week. Moreover, our findings indicates the there is a vulnerability employment for elderly migrants, because do not possess any kind of job contract with their employer, which make push them towards a labor exploitation, including lack of job stability. Migrants work as a daily basis and some of them work in a monthly and weekly basis. In an interview two migrants said: employer do not want to keep us for longer time, because they knows that we are not much productive and physically strong as young people are... so they prefer to give job on daily or weekly basis... and if they likes they move extending the period.. and if at point of time they do not like or they get a young person immediately replace us... This study also explored that elderly migrants faces many time physical violence, labor exploitation and racial discrimination from their employers, which is very high in the case of female elderly migrants.

We can conclude that, though the elderly migrate to Monterrey in a hope of better the socioeconomic status, but once they reach to destination the reality is different. They are living in a precarious situation and exploitative environment. Thus, it is important for government to formulate new public policies to protect our elderly people. In Mexico, some states have pension program for old people, every month government provides 500 to 1000 pesos to more than 70 years old person. But, it feels that this program is not sufficient, thus elderly people are migrating to cities.

\section{References}

1. Capron, Guénola and Arellano, Salomón González (2010). Movilidad residencial de los adultos mayores y trayectorias de vida familiares en la Zona Metropolitana de Valle de México, Alteridades, Vol.20, No.39 México.

2. ECLAC (Economic Commission for Latin America and the Caribbean) (2003). Regional strategy for the implementation in Latin America and the Caribbean of the Madrid international plan of action on ageing, Santiago, Chile, 19-21 November.

3. INEGI (Instituto Nacional de Estadísticas y Geografía) (2012). Estadísticas a Propósito del día del Niño, datos nacionales, Aguascalientes, AGS., Abril.

4. Kanaiaupuni, Shawn (2000). Leaving Parents Behind: Migration and Elderly Living Arrangements in Mexico, CDE Working Paper No. 99-16, Center for Demography and Ecology, University of Wisconsin-Madison

5. Longino, C.F (1992). The forest and the tress: Micro level considerations in the study of geographic mobility in old age. In Elderly Migration and Population Redistribution, ed. A Rogers, 23-24, London, England, Belhaven Press.

6. Northcott, H.C. (1988). Changing residence: The geographic mobility of elderly Canadians, Toronto, Ontario, Butterworths.

7. Partida-Bush, Virgilio (2005). Demographic transition, demographic bonus and ageing in Mexico, in Population Division: Department of Economic and Social 
Affairs, United Nations expert group meeting on social and economic implications of changing population age structures, UN/POP/PD/2005/16, Mexico City, Mexico.

8. Rhoda, Richard and Burton, Tony (2010). Geo-Mexico: the geography and dynamics of modern Mexico, Frostburg State University, MD.

9. Rogers, A, ed (1992). Elderly migrants and population redistribution. London, England: Belhaven Press.

10. United Nations (2011a). World Population Prospects: the 2010 Revision, Department of Economic and Social Affairs, Population Division, New York, USA.

11. United Nations (2011b). World Population Ageing - Profiles of Ageing 2011, Department of Economic and Social Affairs, Population Division, CD-ROM Edition, New York, USA.

12. Valerio, Christy (1997). Elderly Americans: Where They Choose to Retire, Garland Publication.

13. Wiseman, R.F. (1980). Spatial aspects of Aging. Association of American Geographers Resources. Paper for College Geography, No. 78-4, Washington, DC. Association of American Geographers.

14. Wong, Rebeca, Espinoza, Mónica, Palloni, Alberto (2007). Adultos mayores mexicanos en contexto socioeconómico amplio: salud y envejecimiento, Salud Pública de México, Vol. 49, No. 4, Cuernavaca. 
Figure 1: Population distribution according to age groups in Mexico during 1950-2010

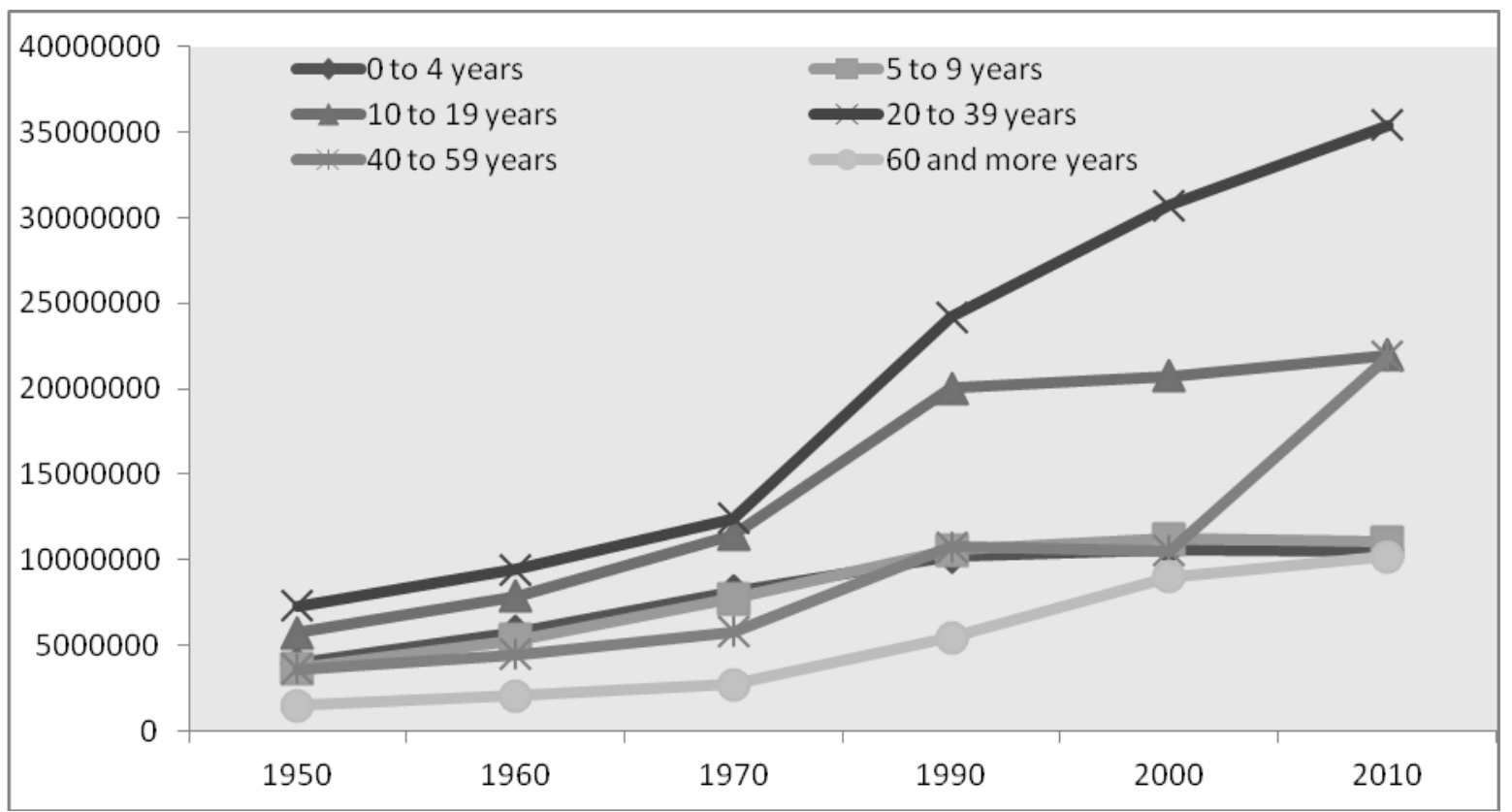


Figure 2: Infant and elderly population distribution in Mexico during 1990-2010

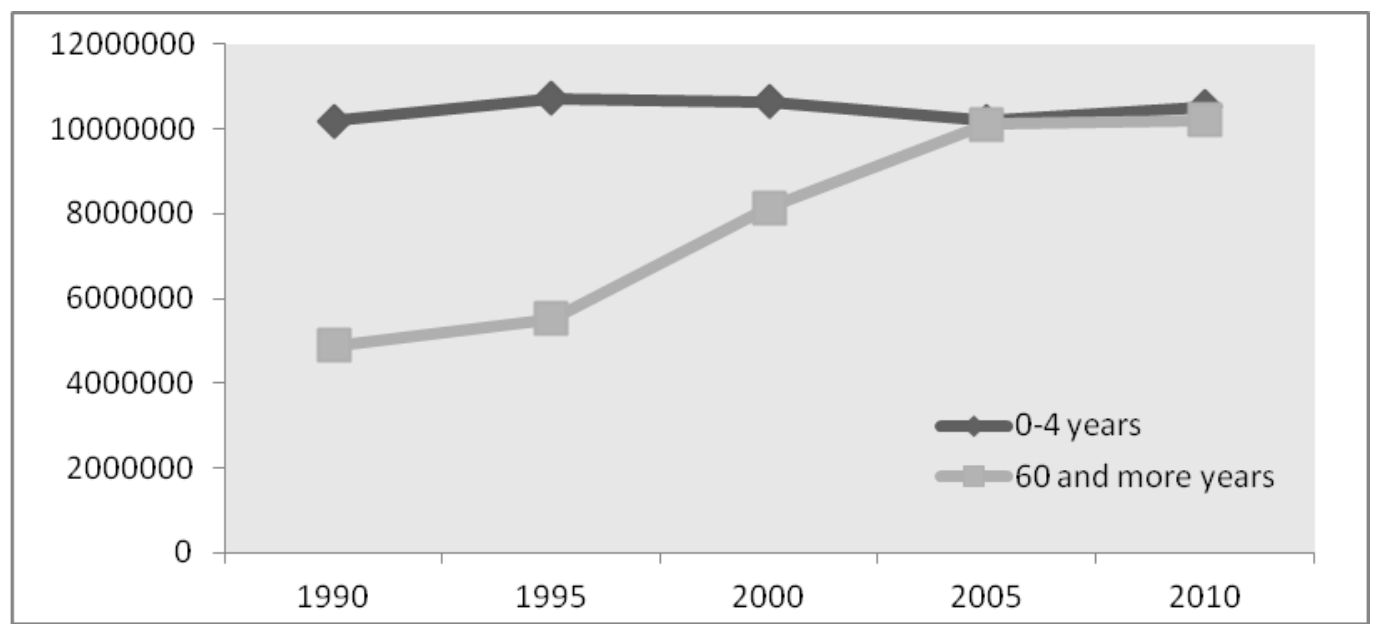


Figure 3: Number of elderly migrants in informal sector in Monterrey

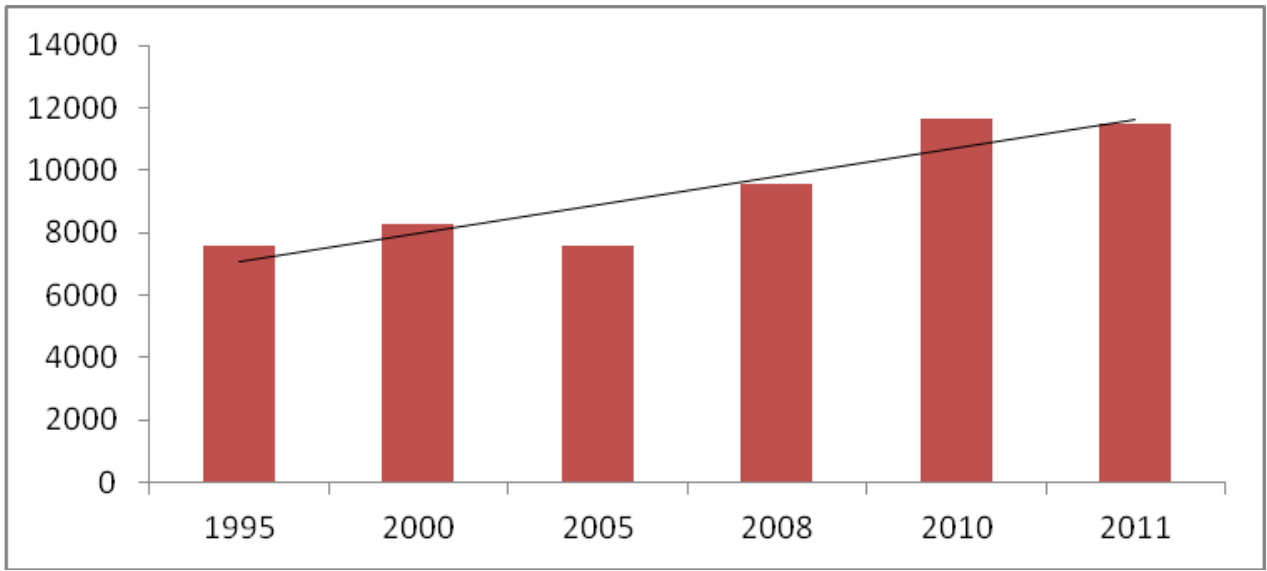


Table 1: Demographic characteristics of elderly people in Monterrey

\begin{tabular}{|l|l|l|}
\hline Elderly migrants & Men & Women \\
\hline Age & & \\
Young old & 62.0 & 65.9 \\
Old old & 31.0 & 29.5 \\
Very old & 6.9 & 4.5 \\
& & \\
Education & & \\
Illiterate & 10.3 & 15.9 \\
Upto primary & 43.7 & 52.2 \\
Upto secondary & 33.3 & 26.1 \\
Bachelor and more & 12.6 & 5.8 \\
\hline
\end{tabular}




\section{Macrothink}

Table 2: Family dynamic and living arrangement of elderly migrants in Monterrey

\begin{tabular}{|l|l|l|}
\hline Elderly migrants & Men & Women \\
\hline Marital status & & \\
Never married & 4.6 & 1.4 \\
Married/Living with partner & 63.2 & 49.3 \\
Widow & 21.8 & 34.8 \\
Divorced and separated & 10.3 & 14.5 \\
& & \\
Currently living with & & \\
Spouse & 57.5 & 44.9 \\
Sons/daughters & 17.2 & 33.3 \\
Others (brothers, sisters and neighbors) & 25.2 & 21.7 \\
& & \\
Number of children & & 27.9 \\
1-2 & 13.9 & 41.2 \\
3-4 & 43.0 & 30.9 \\
More than 4 & 43.0 & \\
\hline
\end{tabular}




\section{Macrothink}

Table 3: Variables of standard of living index (SLI) of elderly migrants

\begin{tabular}{|c|c|}
\hline Standard of living & Variables \\
\hline High & $\begin{array}{l}\text { Elderly migrants have: } \\
\text { - own house with more than } 4 \text { rooms } \\
\text { - posses least two vehicles } \\
\text { - posses all kind of electronic assets } \\
\text { and air condition }\end{array}$ \\
\hline Medium & $\begin{array}{l}\text { Elderly migrants have: } \\
\text { - a rented house with } 3 \text { to } 4 \text { rooms } \\
\text { - posses all kind of electronic goods } \\
\text { - posses at least one vehicles } \\
\text { - no air condition in their house }\end{array}$ \\
\hline Low & $\begin{array}{l}\text { Elderly migrants: } \\
\text { - do not have at least a rented house } \\
\text { they are staying with their friends } \\
\text { or in hurt } \\
\text { - do not posses and electronic goods } \\
\text { as well as car and air condition }\end{array}$ \\
\hline
\end{tabular}


Figure 4: Standard of Living Index (SLI) of elderly migrants in Monterrey

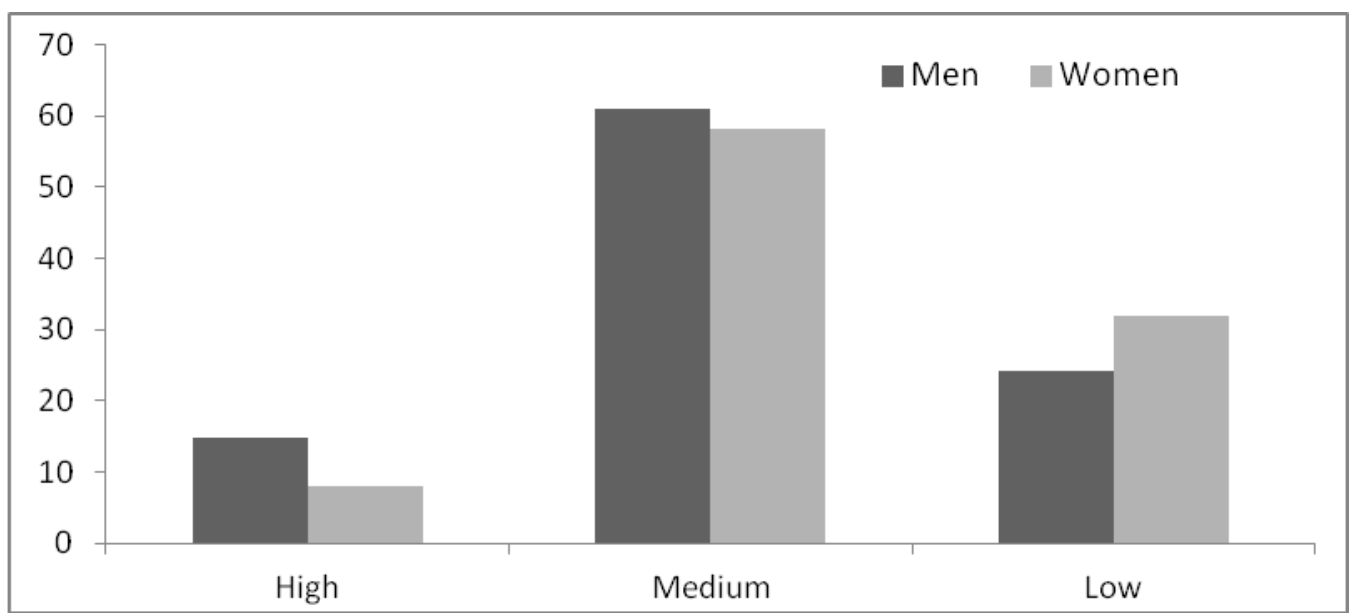




\section{Macrothink}

Table 4: Current income source of elderly migrants in Monterrey

\begin{tabular}{|l|l|l|}
\hline Elderly migrants & Men & Women \\
\hline Street vendor & 23.0 & 33.3 \\
Domestic servant & 4.6 & 31.9 \\
Sweeper & 16.1 & 18.8 \\
Taxi driver & 10.3 & 0 \\
Construction laborer & 16.1 & 1.4 \\
Office secretary & 0 & 4.3 \\
Mechanic & 10.3 & 0 \\
Packaging & 8.0 & 7.2 \\
Others & 11.5 & 2.9 \\
\hline
\end{tabular}




\section{Macrothink}

Table 5: Support receive from children by their elderly migrants in Monterrey

\begin{tabular}{|l|l|l|}
\hline Elderly migrants & Men & Women \\
\hline Financial & 59.3 & 77.9 \\
Instrumental & 29.1 & 22.1 \\
Emotional & 54.7 & 58.8 \\
\hline
\end{tabular}




\section{Macrothink}

Table 6: Monthly Income of elderly migrants in Monterrey

\begin{tabular}{|l|l|l|}
\hline Salary & Men & Women \\
\hline Less than 1500 & 12.6 & 24.6 \\
$1501-3000$ & 42.5 & 43.5 \\
$3001-4000$ & 14.9 & 18.8 \\
More than 4000 & 29.9 & 13.0 \\
\hline
\end{tabular}


Table 7: Hours and Days of working of elderly migrants in Monterrey

\begin{tabular}{|l|l|l|}
\hline Hours/Days & Men & Women \\
\hline Hours of Working & & \\
Less than 5 hours & 27.6 & 33.3 \\
6 to 8 hours & 51.7 & 50.0 \\
More than 9 hours & 20.7 & 19.9 \\
& & \\
Days of working & & \\
1 to 4 days & 12.6 & 7.2 \\
5 to 6 days & 55.2 & 60.3 \\
More than 6 days & 32.2 & 29.5 \\
\hline
\end{tabular}




\section{Macrothink}

Table 8: Dynamic of employment of elderly migrants in Monterrey

\begin{tabular}{|l|l|l|}
\hline Dynamic/employment & Men & Women \\
\hline Job Contract & & \\
Yes & 17.2 & 17.9 \\
No & 82.8 & 82.1 \\
Job stability & & \\
Daily wage contract & 64.4 & 75.4 \\
Monthly contract & 20.7 & 13.0 \\
Few weeks contract & 14.9 & 11.6 \\
& & \\
Work shift & & \\
Morning & 71.3 & 62.3 \\
Afternoon & 19.5 & 36.2 \\
Night & 9.2 & 1.4 \\
\hline
\end{tabular}




\section{Macrothink}

Table 9: Violence and laboral exploitation against elderly migrants

\begin{tabular}{|l|l|l|}
\hline Violence & Men & Women \\
\hline Physical Violence & 46.2 & 53.8 \\
Laboral exploitation & 46.7 & 53.3 \\
Racial discrimination & 47.8 & 52.2 \\
\hline
\end{tabular}

Out of total interviews: Physical violence (8.3\%), laboral exploitation (19.2\%) and discrimination $(29.5 \%)$. 